\title{
Processing of yttrium-doped barium zirconate for high proton conductivity
}

\author{
Peter Babilo \\ Materials Science, California Institute of Technology, Pasadena, California 91125 \\ Tetsuya Uda \\ Materials Science, California Institute of Technology, Pasadena, California 91125; and Materials \\ Science and Engineering, Kyoto University, Kyoto, Japan 606-8501 \\ Sossina M. Haile ${ }^{\text {a) }}$ \\ Materials Science, California Institute of Technology, Pasadena, California 91125
}

(Received 4 May 2006; accepted 25 January 2007)

\begin{abstract}
The factors governing the transport properties of yttrium-doped barium zirconate (BYZ) have been explored, with the aim of attaining reproducible proton conductivity in well-densified samples. It was found that a small initial particle size $(50-100 \mathrm{~nm})$ and high-temperature sintering $\left(1600{ }^{\circ} \mathrm{C}\right)$ in the presence of excess barium were essential. By this procedure, $\mathrm{BaZr}_{0.8} \mathrm{Y}_{0.2} \mathrm{O}_{3-\delta}$ with $93 \%$ to $99 \%$ theoretical density and total (bulk plus grain boundary) conductivity of $7.9 \times 10^{-3} \mathrm{~S} / \mathrm{cm}$ at $600{ }^{\circ} \mathrm{C}$ [as measured by alternating current (ac) impedance spectroscopy under humidified nitrogen] could be reliably prepared. Samples sintered in the absence of excess barium displayed yttria-like precipitates and a bulk conductivity that was reduced by more than 2 orders of magnitude.
\end{abstract}

\section{INTRODUCTION}

Doped perovskites, such as barium cerate $\left(\mathrm{BaCeO}_{3}\right)$, strontium cerate $\left(\mathrm{SrCeO}_{3}\right)$, and barium zirconate $\left(\mathrm{BaZrO}_{3}\right)$, have been widely studied in recent years as proton conducting electrolytes for a variety of electrochemical devices including fuel cells. Among the fuel cell studies, the most impressive results are arguably those of Iguchi et al. ${ }^{1}$ Using yttrium-doped barium cerate as an electrolyte, these authors demonstrated power densities of $570 \mathrm{~mW} / \mathrm{cm}^{2}$ at $430{ }^{\circ} \mathrm{C}$ and $780 \mathrm{~mW} / \mathrm{cm}^{2}$ at $510{ }^{\circ} \mathrm{C}$ under air/hydrogen conditions. To circumvent the detrimental reaction of barium cerate with $\mathrm{CO}_{2}$, which would otherwise result in the formation of $\mathrm{BaCO}_{3}$ and $\mathrm{CeO}_{2}$, the authors protected the thin electrolyte by depositing it onto a dense layer of palladium foil, a wellknown hydrogen separation material. In contrast to barium cerate, barium zirconate, which exhibits proton conduction by a similar mechanism, ${ }^{2}$ is known to be stable in $\mathrm{CO}_{2}$-containing atmospheres. ${ }^{3}$ Thus, fuel cells based on this electrolyte would not require elaborate solutions for ensuring cell longevity. However, the conductivity of doped barium zirconate as reported from 12 independent groups (Table $\mathrm{I}^{4-15}$ ) varies widely, from a low of $\sim 1 \times 10^{-6}$ to a high of $1 \times 10^{-2} \mathrm{~S} / \mathrm{cm}$ at $600{ }^{\circ} \mathrm{C}$, introducing major challenges for its implementation in

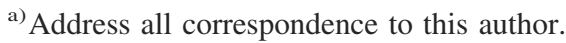

e-mail: smhaile@caltech.edu

DOI: $10.1557 /$ JMR.2007.0163
}

any real device and raising fundamental questions regarding the proton transport mechanism.

The earliest studies of doped barium zirconate, which appeared in the early 1990s, suggested that this material exhibits poor proton conductivity compared with doped barium cerate. Although their reported values differ by 2 orders of magnitude, Iwahara et al., ${ }^{4}$ Manthiram et al., ${ }^{5}$ and Slade et al. ${ }^{6}$ all agreed that the conductivity of the zirconate is no more than $1.2 \times 10^{-4} \mathrm{~S} / \mathrm{cm}$ at $600{ }^{\circ} \mathrm{C}$. The understanding of the properties of barium zirconate was revised substantially in 1999. In that year Kreuer ${ }^{2}$ reported the conductivity of yttrium-doped barium zirconate (BYZ) to be $\sim 5 \times 10^{-5} \mathrm{~S} / \mathrm{cm}$ at just $140^{\circ} \mathrm{C}$, and this was quickly confirmed by Bohn and Schober in $2000 .{ }^{7}$ In a later paper, Kreuer noted the poor reproducibility of conductivity measurements of barium zirconate $^{11}$ and argued that this is connected to the difficulty in fabricating polycrystalline compacts of the material. In the present study, we explore the sample preparation steps that are responsible for this poor reproducibility and report a methodology for consistently obtaining high-density, high-conductivity barium zirconate with transport properties comparable to the best values reported in the literature.

\section{EXPERIMENTAL PROCEDURE}

The specific composition selected in this study was $\mathrm{BaZr}_{0.8} \mathrm{Y}_{0.2} \mathrm{O}_{3-x}$ (BYZ20). To obtain reproducible sintering behavior and electrical properties, a wide range 
TABLE I. Conductivity of doped $\mathrm{BaZrO}_{3}$ as reported in the literature (conductivity of barium cerate also provided for comparison).

\begin{tabular}{|c|c|c|c|c|}
\hline Composition & Sintering conditions & Conductivity (bulk or total) ${ }^{\mathrm{a}}$ & Conductivity measurement conditions & Ref. \\
\hline $\mathrm{BaZr}_{0.95} \mathrm{In}_{0.05} \mathrm{O}_{3-x}$ & $1500-1650{ }^{\circ} \mathrm{C}$ for $10 \mathrm{~h}$ in air & $1.2 \times 10^{-4} \mathrm{~S} / \mathrm{cm}$ (total) at $600^{\circ} \mathrm{C}$ & $\mathrm{H}_{2}$ (wet) & 4 \\
\hline $\mathrm{BaZr}_{0.9} \mathrm{In}_{0.1} \mathrm{O}_{3-x}$ & $1350{ }^{\circ} \mathrm{C}$ for $40 \mathrm{~h}$ & $5.0 \times 10^{-5} \mathrm{~S} / \mathrm{cm}$ (bulk) at $600^{\circ} \mathrm{C}$ & Wet $\mathrm{N}_{2}$ & 5 \\
\hline $\mathrm{BaZr}_{0.9} \mathrm{Y}_{0.1} \mathrm{O}_{3-x}$ & $1400{ }^{\circ} \mathrm{C}$ for $10 \mathrm{~h}$ in air & $1.3 \times 10^{-6} \mathrm{~S} / \mathrm{cm}$ (bulk) at $605^{\circ} \mathrm{C}$ & Wet $\mathrm{N}_{2}$ (room temperature water) & 6 \\
\hline $\mathrm{BaZr}_{0.9} \mathrm{Y}_{0.1} \mathrm{O}_{3-x}$ & $1715^{\circ} \mathrm{C}$ for $30 \mathrm{~h}$ in air & $3.0 \times 10^{-3} \mathrm{~S} / \mathrm{cm}$ (bulk) at $600^{\circ} \mathrm{C}$ & Wet air & 7 \\
\hline $\mathrm{BaZr}_{0.9} \mathrm{Y}_{0.1} \mathrm{O}_{3-x}$ & $1800{ }^{\circ} \mathrm{C}$ for $5 \mathrm{~h}$ in air & $1.1 \times 10^{-3} \mathrm{~S} / \mathrm{cm}$ (total) at $600^{\circ} \mathrm{C}$ & Wet $\mathrm{H}_{2}\left(p_{\mathrm{H}_{2} \mathrm{O}}=0.017 \mathrm{~atm}\right)$ & 8 \\
\hline $\mathrm{BaZr}_{0.93} \mathrm{Y}_{0.07} \mathrm{O}_{3-x}$ & $1700{ }^{\circ} \mathrm{C}$ for $1 \mathrm{~h}$ & $5 \times 10^{-4} \mathrm{~S} / \mathrm{cm}$ (total) at $600^{\circ} \mathrm{C}$ & Wet air (room temperature water) & 9 \\
\hline $\mathrm{BaZr}_{0.95} \mathrm{Y}_{0.05} \mathrm{O}_{3-x}$ & $1350-1400{ }^{\circ} \mathrm{C}$ for $20-40 \mathrm{~h}$ in air & $1.8 \times 10^{-6} \mathrm{~S} / \mathrm{cm}$ (bulk) at $605^{\circ} \mathrm{C}$ & Wet $\mathrm{N}_{2}\left(p_{\mathrm{H}_{2} \mathrm{O}}=0.031 \mathrm{~atm}\right)$ & 10 \\
\hline $\mathrm{BaZr}_{0.85} \mathrm{Y}_{0.15} \mathrm{O}_{3-x}$ & $1700{ }^{\circ} \mathrm{C}$ for $20 \mathrm{~h}$ & $1.6 \times 10^{-3} \mathrm{~S} / \mathrm{cm}$ (total) at $600^{\circ} \mathrm{C}$ & Wet $\mathrm{N}_{2}\left(p_{\mathrm{H}_{2} \mathrm{O}}=0.023 \mathrm{~atm}\right)$ & 11 \\
\hline $\begin{array}{c}\mathrm{Ba}_{1.1} \mathrm{Zr}_{0.9} \mathrm{Y}_{0.1} \mathrm{O}_{3-x}(10 \% \\
\text { excess } \mathrm{BaO} \text { before }\end{array}$ & & & & \\
\hline sintering) & $1500{ }^{\circ} \mathrm{C}$ for $24 \mathrm{~h}$ & $9 \times 10^{-4} \mathrm{~S} / \mathrm{cm}$ (total) at $500^{\circ} \mathrm{C}$ & Wet air & 12 \\
\hline \multirow[t]{2}{*}{$\mathrm{BaZr}_{0.93} \mathrm{Y}_{0.07} \mathrm{O}_{3-x}$} & $1650^{\circ} \mathrm{C}$ for $10 \mathrm{~h}$ in air & $3.8 \times 10^{-3} \mathrm{~S} / \mathrm{cm}$ (total) at $600^{\circ} \mathrm{C}$ & Wet $\mathrm{N}_{2}\left(p_{\mathrm{H}_{2} \mathrm{O}}=0.025 \mathrm{~atm}\right)$ & 13 \\
\hline & & $4.2 \times 10^{-3} \mathrm{~S} / \mathrm{cm}$ (total) at $600^{\circ} \mathrm{C}$ & Wet air $\left(p_{\mathrm{H}_{2} \mathrm{O}}=0.025 \mathrm{~atm}\right)$ & \\
\hline $\mathrm{BaZr}_{0.9} \mathrm{Y}_{0.1} \mathrm{O}_{3-x}$ & $1400^{\circ} \mathrm{C}$ & $2.8 \times 10^{-4} \mathrm{~S} / \mathrm{cm}$ (bulk) at $600^{\circ} \mathrm{C}$ & Wet $\mathrm{Ar}-5 \% \mathrm{H}_{2},\left(p_{\mathrm{H}_{2} \mathrm{O}}=0.03 \mathrm{~atm}\right)$ & 14 \\
\hline $\mathrm{BaZr}_{0.95} \mathrm{Y}_{0.05} \mathrm{O}_{3-x}$ & $1800{ }^{\circ} \mathrm{C}$ for $20 \mathrm{~h}$ in air & $1.0 \times 10^{-2} \mathrm{~S} / \mathrm{cm}$ at $600^{\circ} \mathrm{C}$ & Wet $\mathrm{Ar}+\mathrm{O}_{2}\left(p_{\mathrm{H}_{2} \mathrm{O}}=0.023 \mathrm{~atm}\right)$ & 15 \\
\hline $\mathrm{BaCe}_{0.9} \mathrm{Y}_{0.1} \mathrm{O}_{3-x}$ & $1700{ }^{\circ} \mathrm{C}$ for $10 \mathrm{~h}$ in air & $1.1 \times 10^{-2}$ (total) at $600^{\circ} \mathrm{C}$ & Wet $\mathrm{H}_{2}\left(p_{\mathrm{H}_{2} \mathrm{O}}=0.017 \mathrm{~atm}\right)$ & 8 \\
\hline
\end{tabular}

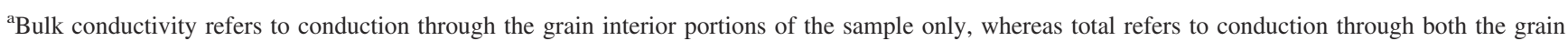
interiors and the grain boundaries.

Note: All data collected using Pt electrodes with the exception of Mintharam et al. (Ref. 5), in which Ag electrodes were utilized. Iguchi et al. ${ }^{15}$ did not report the electrode material.

of processing conditions were examined. Ultimately, it was found that both solid-state and chemical synthesis were suitable as long as the crystallite size of the loose powder was reduced to the 50 to $100 \mathrm{~nm}$ range prior to densification. Samples prepared from powders obtained by a glycine-nitrate combustion synthesis process ${ }^{16}$ are described here. Starting materials were high-purity $\mathrm{Ba}\left(\mathrm{NO}_{3}\right)_{2}$ (Alfa Aesar, Ward Hill, MA, 99.95\% purity), $\mathrm{Y}\left(\mathrm{NO}_{3}\right)_{3} \cdot 6 \mathrm{H}_{2} \mathrm{O}$ (Alfa Aesar $99.9 \%$ purity), and $\mathrm{ZrO}\left(\mathrm{NO}_{3}\right)_{2} \cdot x \mathrm{H}_{2} \mathrm{O}$ (Alfa Aesar $99.9 \%$ purity, where $x=$ 2.3 was determined by thermogravimetric analysis). The appropriate molar ratios of nitrates and glycine $\left(\mathrm{NH}_{2} \mathrm{CH}_{2} \mathrm{COOH}\right)$ were mixed in a minimum volume of deionized water to obtain a transparent solution. A glycine-to-nitrate ratio of 1 to 2 was used. The aqueous solution was dehydrated on a hot plate at a temperature of $150{ }^{\circ} \mathrm{C}$, generating a viscous liquid. Upon complete evaporation of the water, the viscous liquid autoignited to produce the desired powders. After autoignition, powders were calcined at $1250{ }^{\circ} \mathrm{C}$ for $5 \mathrm{~h}$ to yield wellcrystallized BYZ20, which were subsequently attritor milled at $500 \mathrm{rpm}$ for $5 \mathrm{~h}$ to produce uniform particles with an approximate size of 20 to $100 \mathrm{~nm}$, as determined by scanning electron microscopy (SEM) (figure not shown here).

The fine powders so prepared were mixed, using an agate mortar, with a binder solution consisting of $200 \mathrm{ml}$ of water, $2 \mathrm{~g}$ of polyvinyl alcohol (PVA), $1 \mathrm{ml}$ of glycerin, and $10 \mathrm{ml}$ of ethanol. The ratio of binder solution to oxide powder was approximately 1 to 7 by mass. The granulated power was then passed through a 100-mesh sieve to remove agglomerates larger than $\sim 150 \mu \mathrm{m}$. Green pellets were obtained by uniaxial pressing under a pressure of $400 \mathrm{MPa}$ for $1 \mathrm{~min}$. On firing, the binder was removed by holding the pellets at $600{ }^{\circ} \mathrm{C}$ (ramp of $1{ }^{\circ} \mathrm{C} / \mathrm{min}$ ) under ambient air for a period of $30 \mathrm{~min}$. In the final sintering step, samples were surrounded by a powder mixture of $\mathrm{BYZ}$ and small amount of $\mathrm{BaCO}_{3}$ (about $10 \mathrm{wt} \%$ ), as shown in Fig. 1. Sintering was carried out under flowing oxygen at $1600{ }^{\circ} \mathrm{C}$ (ramp of $5{ }^{\circ} \mathrm{C} / \mathrm{min}$ to $1000{ }^{\circ} \mathrm{C}$, followed by a ramp of $1{ }^{\circ} \mathrm{C} / \mathrm{min}$ ) for a period of 4 to $24 \mathrm{~h}$. To probe the effect of sintering procedure on conductivity, samples not enclosed in excess barium were also prepared. The two types of samples are hereafter referred to as "covered" and "uncovered," respectively.

The resulting materials were characterized by a broad
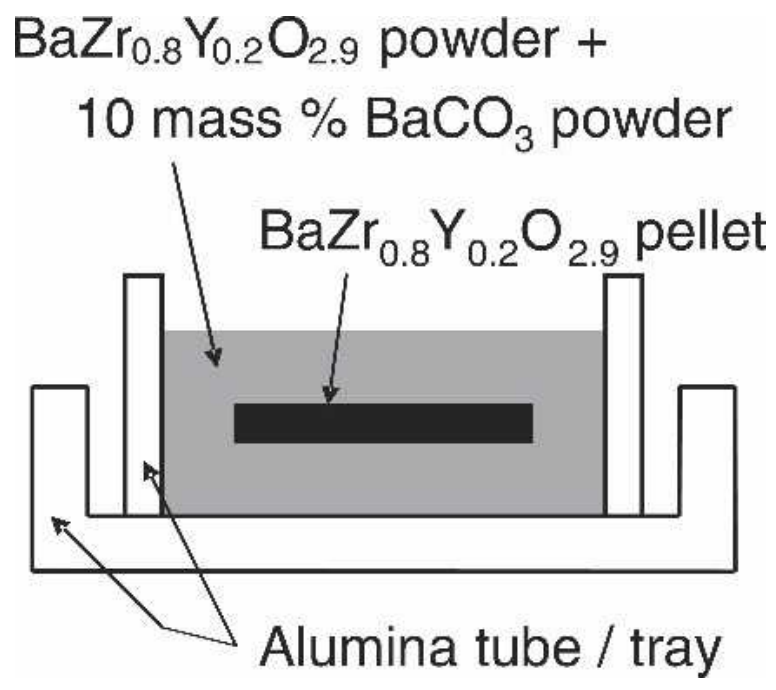

FIG. 1. Sintering configuration: BYZ20 green pellet covered with a powder mixture of $\mathrm{BYZ} 20$ and $\mathrm{BaCO}_{3}$ (about 10 mass\%). 
range of techniques. The density of the sintered disks was measured by the Archimedes method using deionized water. The microstructures of sintered pellets were observed with a LEO 1550VP field emission scanning electron microscope (10 kV excitation voltage; Carl Zeiss, Oberkochen, Germany). X-ray diffraction (XRD) patterns were collected from the BYZ powder and the polished surfaces of sintered pellets using a Philips X'Pert PRO diffractometer $\left(\mathrm{Cu} \mathrm{K} \mathrm{K}_{\alpha}\right.$ radiation; Eindhoven, The Netherlands). Intensities were obtained in the $2 \theta$ range between $20^{\circ}$ and $80^{\circ}$ with an effective step size of $0.02^{\circ}$ (due to the wide-angle data collection of the detector) and a measuring time of $8 \mathrm{~s}$ at each step. Patterns collected from densified pellets were then corrected for displacement errors. In addition to phase analysis, x-ray patterns were also utilized to determine cell parameters by Rietveld refinement as implemented in the X'Pert Plus software. Quantitative elemental microanalyses were conducted with a JEOL 8200 electron microprobe (Tokyo, Japan) operated at $15 \mathrm{kV}$ and $25 \mathrm{nA}$ in a $10 \mu \mathrm{m}$ beam mode. Quantitative measurements of the average chemical composition were obtained in the covered and uncovered sintered pellets. In this analysis, BYZ20 covered (sintered for $24 \mathrm{~h}$ ) was used as the standard against which the uncovered samples were compared. Characteristic xray emission intensities were converted to chemical weight percents using the program CITZAF. ${ }^{17}$

The conductivity of sintered pellets was measured by impedance spectroscopy over the frequency range $10^{2}$ to $10^{6} \mathrm{~Hz}$ using a 4284A LCR meter (Agilent, Santa Clara, $\mathrm{CA}$ ) with an applied alternating current (ac) voltage amplitude of $50 \mathrm{mV}$. Unless stated otherwise, reported data are those obtained from BYZ20 sintered for $24 \mathrm{~h}$. Silver electrodes were applied onto the surfaces of polished samples by brush painting colloidal silver paint (No. 16032, Ted Pella, Inc., Redding, CA). A preliminary examination of $\mathrm{Pt}$ as an electrode material was also carried out, and the results are briefly presented here. Water was incorporated into the samples by exposure to watersaturated nitrogen $\left(p_{\mathrm{H}_{2} \mathrm{O}}=0.031 \mathrm{~atm}\right)$ at $300{ }^{\circ} \mathrm{C}$ for $8 \mathrm{~h}$ The dimensions of the pellets were 0.65 to $0.73 \mathrm{~mm}$ in thickness and 0.69 to $0.71 \mathrm{~cm}^{2}$ in area. Data were collected under $\mathrm{H}_{2} \mathrm{O}$-saturated nitrogen $\left(p_{\mathrm{H}_{2} \mathrm{O}}=0.031 \mathrm{~atm}\right)$ over the temperature range of 75 to $600{ }^{\circ} \mathrm{C}$ in $25^{\circ} \mathrm{C}$ intervals with an equilibration time of $30 \mathrm{~min}$ before each measurement. The resulting impedance spectra were analyzed in terms of an equivalent circuit model using the software package Zview (Scribner Associates Inc., Southern Pines, NC) and an appropriate configuration of resistance $(R)$, and constant phase $(Q)$ elements with respective impedances $Z_{\mathrm{R}}=R$ and $Z_{\mathrm{Q}}=\left(Y(j \omega)^{n}\right)^{-1}{ }^{18}$ where $j=\sqrt{-1}, \omega=$ frequency, $Y$ and $n$ are constants, and $n$ ranges between 0 and 1 .

We note that while most researchers take doped barium zirconate to be a single-phase, cubic material (comparable to the undoped composition), Kreuer et al. have reported that at the intermediate $\mathrm{Y}$ content used here barium zirconate adopts a tetragonal structure, reverting to a cubic phase a high $(25 \%) \mathrm{Y}$ doping. ${ }^{19}$ In contrast, Yamaguchi et al. have reported that, in the range of $8 \%$ to $40 \%$ yttrium, doped barium zirconate phase sintered at $1600{ }^{\circ} \mathrm{C}$ separates into two perovskite phases with differing dopant concentrations. ${ }^{20}$ No attempt has been made here to address such structural questions. Should phase separation or anisotropy occur, the reported results reflect the average properties.

\section{RESULTS AND DISCUSSION}

\section{A. Densification, phase formation, and stoichiometry}

The relative density of (covered) sintered pellets of BYZ prepared by the careful procedures outlined above rose from $93 \%$ to $99 \%$ (with respect to the density of undoped barium zirconate, $6.21 \mathrm{~g} / \mathrm{cm}^{3}$ ) with increasing sintering time (Fig. 2). A scanning electron micrograph (Fig. 3) of a fracture surface in the $24 \mathrm{~h}$ covered sample confirms the high density. The average grain size is approximately $0.46 \mu \mathrm{m}$, with a wide distribution of grain sizes $(0.2-1 \mu \mathrm{m})$. This small grain size is consistent with the observation that BYZ is highly refractory with low rates of grain growth under typical sintering conditions. ${ }^{21}$ The step of covering the samples had little effect on density, but tended to yield materials with slightly smaller grain sizes.

A comparison of the XRD patterns of covered and uncovered BYZ20 pellets is presented in Fig. 4. The data reveal quite clearly that even after just a few hours of exposure to $1600{ }^{\circ} \mathrm{C}$, the uncovered pellets show a decrease in perovskite cell constant and display the presence of an impurity phase with a high intensity peak at $29.2^{\circ} 2 \theta$. This phase, also observed by Magrez and

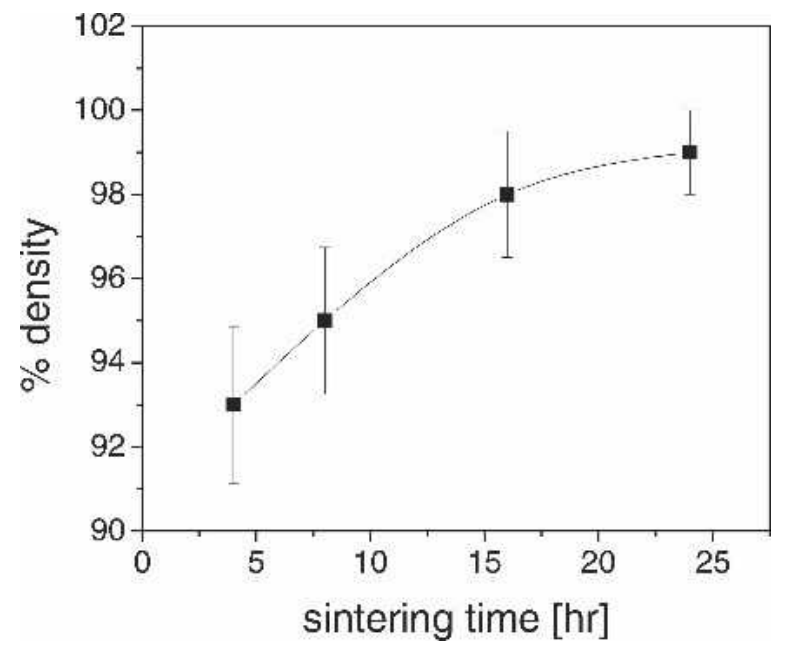

FIG. 2. Density of $\mathrm{BaZr}_{0.8} \mathrm{Y}_{0.2} \mathrm{O}_{3-\delta}$ as a function of sintering time, sintered at $1600{ }^{\circ} \mathrm{C}$ under flowing $\mathrm{O}_{2}$. 


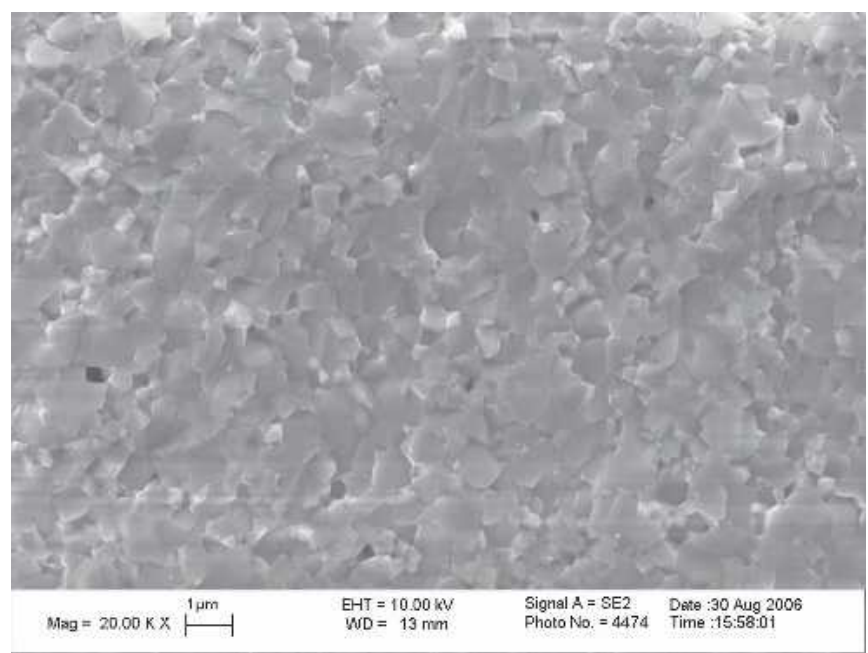

FIG. 3. Scanning electron micrograph of fracture surface of BYZ20 sintered for $24 \mathrm{~h}$ at $1600{ }^{\circ} \mathrm{C}$.

Schober in their study of the high-temperature structural characteristics of $\mathrm{Ba}_{0.99} \mathrm{Zr}_{0.8} \mathrm{Y}_{0.2} \mathrm{O}_{3-\delta},{ }^{22}$ corresponds to a "yttria-like" material ${ }^{23}$ with space group $I a \overline{3}$ and lattice constant approximately $10.59 \AA$. It is to be emphasized that these precipitates occur throughout the bulk of the pellets; the highly disintegrated surface layer (50-100 $\mu \mathrm{m})$ was removed by polishing prior to the collection of the diffraction data. It may be that such precipitates pin grain boundaries and are responsible for the slightly smaller grain sizes in the uncovered sample. The decrease in cell constant on prolonged exposure to high temperatures may be attributed to the transfer of the dopant from the $\mathrm{B}$ to $\mathrm{A}$ site in the $\mathrm{ABO}_{3}$ perovskite as $\mathrm{A}$ sites become vacant due to barium loss. Such behavior is now well documented in barium-deficient, rare-earth-

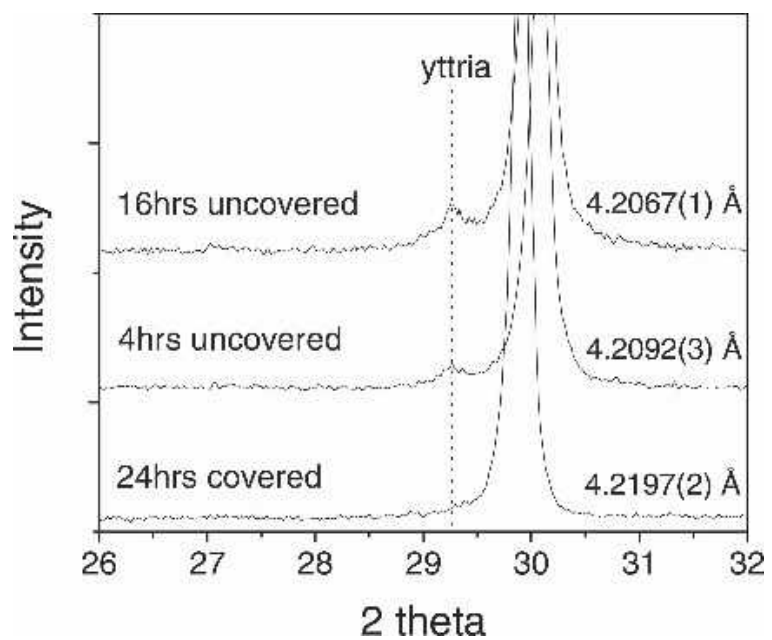

FIG. 4. XRD patterns of BYZ20 pellets sintered at $1600{ }^{\circ} \mathrm{C}$ under the conditions indicated. Number associated with each diffraction pattern is the perovskite unit cell parameter (see text for details).

doped barium cerate. ${ }^{24-26}$ Alternatively, the behavior may result from a reduction of the dopant content in the perovskite with yttria being expelled from the structure to maintain an A-to-B stoichiometric ratio of 1 to 1 . In contrast to the uncovered samples, after even $24 \mathrm{~h}$ of exposure to this same temperature BYZ20 covered with excess powder of the same composition is free of yttria precipitates.

The chemical analysis (Table II) directly shows the uncovered samples to be barium deficient relative to those that were covered during sintering. The molar ratio $\mathrm{Ba} /(\mathrm{Zr}+\mathrm{Y})$ falls from 0.97 for the uncovered sample sintered for $4 \mathrm{~h}$ to 0.95 for the sample sintered for $16 \mathrm{~h}$, in agreement with the observation of an increasing

TABLE II. Summary of chemical analysis of sintered BYZ20 with excess Ba (covered) and without excess Ba (uncovered).

\begin{tabular}{lccc}
\multicolumn{1}{c}{ Sample no. } & Ba, mol/f.u. & Y, mol/f.u. & Zr, mol/f.u. \\
\hline S1 & 1.023944 & 0.175893 & 0.806109 \\
S2 & 1.001058 & 0.183145 & 0.812113 \\
S3 & $1.002477(\mathrm{Zr}+\mathrm{Y})$ \\
S4 & 1.012282 & 0.192313 & 0.804527 \\
S5 & 0.985867 & 0.182078 & 0.807301 \\
24 h covered, average & $1.005 \pm 0.01$ & 0.208789 & 0.800475 \\
S6 & 0.975289 & $0.188 \pm 0.01$ & $0.806 \pm 0.004$ \\
S7 & 0.981355 & 0.195194 & 0.815961 \\
S8 & 0.987645 & 0.189261 & 0.817377 \\
S9 & 0.964130 & 0.187537 & 0.815525 \\
S10 & 0.983761 & 0.191762 & 0.824114 \\
4 h uncovered, average & $0.978 \pm 0.008$ & 0.187945 & 0.817161 \\
S11 & 0.974144 & $0.190 \pm 0.003$ & $0.818 \pm 0.003$ \\
S12 & 0.96377 & 0.195688 & 0.816163 \\
S13 & 0.959533 & 0.184314 & 0.829879 \\
S14 & 0.96602 & 0.198868 & 0.821083 \\
S15 & 0.965264 & 0.191051 & 0.823702 \\
16 h uncovered, average & $0.966 \pm 0.005$ & 0.186103 & 0.827791 \\
\hline \hline
\end{tabular}

Note: Data normalized and reported as moles of cation per formula unit (f.u.). Sample number indicates different positions on the three samples examined. The covered sample. 
intensity for the yttria diffraction peak with increasing sintering time for uncovered samples. We note that even the covered samples showed measurable barium deficiency; however, we focus here on the relative chemical differences between the covered and uncovered samples rather than their absolute chemistries.

Overall, the results provide clear evidence that under typical sintering conditions, $\mathrm{BaZr}_{1-x} \mathrm{Y}_{x} \mathrm{O}_{3-\delta}$ samples decompose to form yttria and volatile barium oxide. The absence of yttria precipitates from covered samples indicates that the volatilization of barium oxide can be kinetically suppressed. A related synthesis procedure has been proposed by Snijkers et al., ${ }^{12}$ who showed that direct addition of excess barium carbonate within the bulk of pressed pellets has a similar effect of suppressing yttria precipitation during the sintering of uncovered samples.

\section{B. Conductivity of BYZ by impedance spectroscopy}

Representative alternating current (ac) impedance spectra of BYZ20 obtained under $\mathrm{N}_{2}-0.03$ atm $\mathrm{H}_{2} \mathrm{O}$ are shown in the Nyquist representation $\left(-Z_{\text {imag }}\right.$ versus $\left.Z_{\text {real }}\right)$ in Fig. 5. Only at the lowest temperatures $\left(<150^{\circ} \mathrm{C}\right)$ do the spectra display clear evidence of a high-frequency arc (arc 1) that extends to the origin. This arc, which yields a relative dielectric constant of 46 , is attributed to the bulk behavior of BYZ20. As the temperature is increased, because the characteristic frequency, $\omega_{0}$, of the bulk processes increases exponentially $\left(\omega_{\mathrm{o}}=1 / R C\right.$, where $R$ is resistance and $C$ is capacitance), the bulk arc becomes inaccessible, and even at just $123{ }^{\circ} \mathrm{C}$ the spectra are dominated by a lower-frequency process (a very typical result). This midfrequency arc (arc 2) is attributed to grain-boundary processes. The "equivalent" relative dielectric constant (that is, one in which the grain-boundary dimensions are not accounted for) implied by this arc is of the order of 6500 . This value is consistent with grainboundary properties, as discussed further below. At the very lowest frequencies, evidence for an even slower process appears in the $222{ }^{\circ} \mathrm{C}$ spectrum (arc 3), which is attributed to the electrode.

As the temperature is further increased, the electrode processes begin to dominate the overall response. By $\sim 370{ }^{\circ} \mathrm{C}$, it is almost impossible to distinguish between bulk and grain-boundary contributions to the electrolyte resistance, and furthermore the electrode processes display evidence of a complex electrochemical reaction pathway, characterized by two or possibly more characteristic time scales. At temperatures greater than about
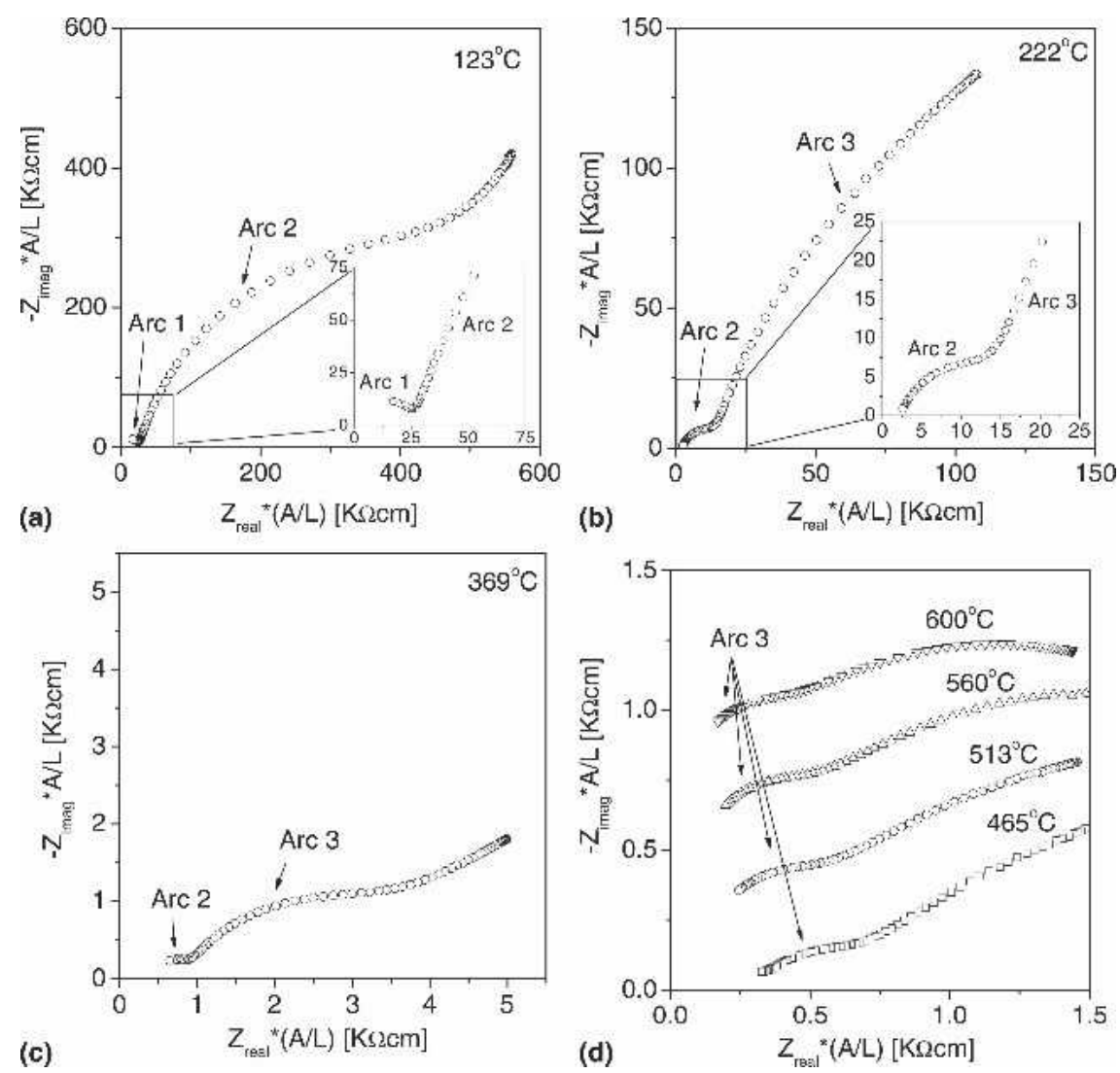

FIG. 5. Nyquist impedance spectra obtained from BYZ20 with Ag electrodes under humidified nitrogen $\left(p_{\mathrm{H}_{2} \mathrm{O}}=0.03\right.$ atm) at the noted temperature (a) $123{ }^{\circ} \mathrm{C}$, (b) $222{ }^{\circ} \mathrm{C}$, (c) $269^{\circ} \mathrm{C}$, and (d) 465 to $600{ }^{\circ} \mathrm{C}$. In (d) data are offset along the imaginary axis in increments of $0.3 \mathrm{~K} \Omega \mathrm{cm}$ for clarity. 
$450{ }^{\circ} \mathrm{C}$, no direct information can be obtained regarding the electrolyte properties. The spectra reflect entirely the electrode processes, and only the displacement of the spectra from the real axis provides any measure of the electrolyte resistance. In the absence of lowertemperature data, misinterpretation of the type of spectra shown in Fig. 5(d) could easily occur. For example, the lower-frequency feature of the electrode response could incorrectly be attributed to the grain-boundary response, and the electrolyte resistance overestimated by a factor of up to 3 at high temperatures. Thus, possible misidentification of the features of the impedance spectra may contribute to the discrepancies in the literature regarding the properties of doped barium zirconate.

Selected results of the examination of Pt as an alternative electrode material are shown in Fig. 6. Here,
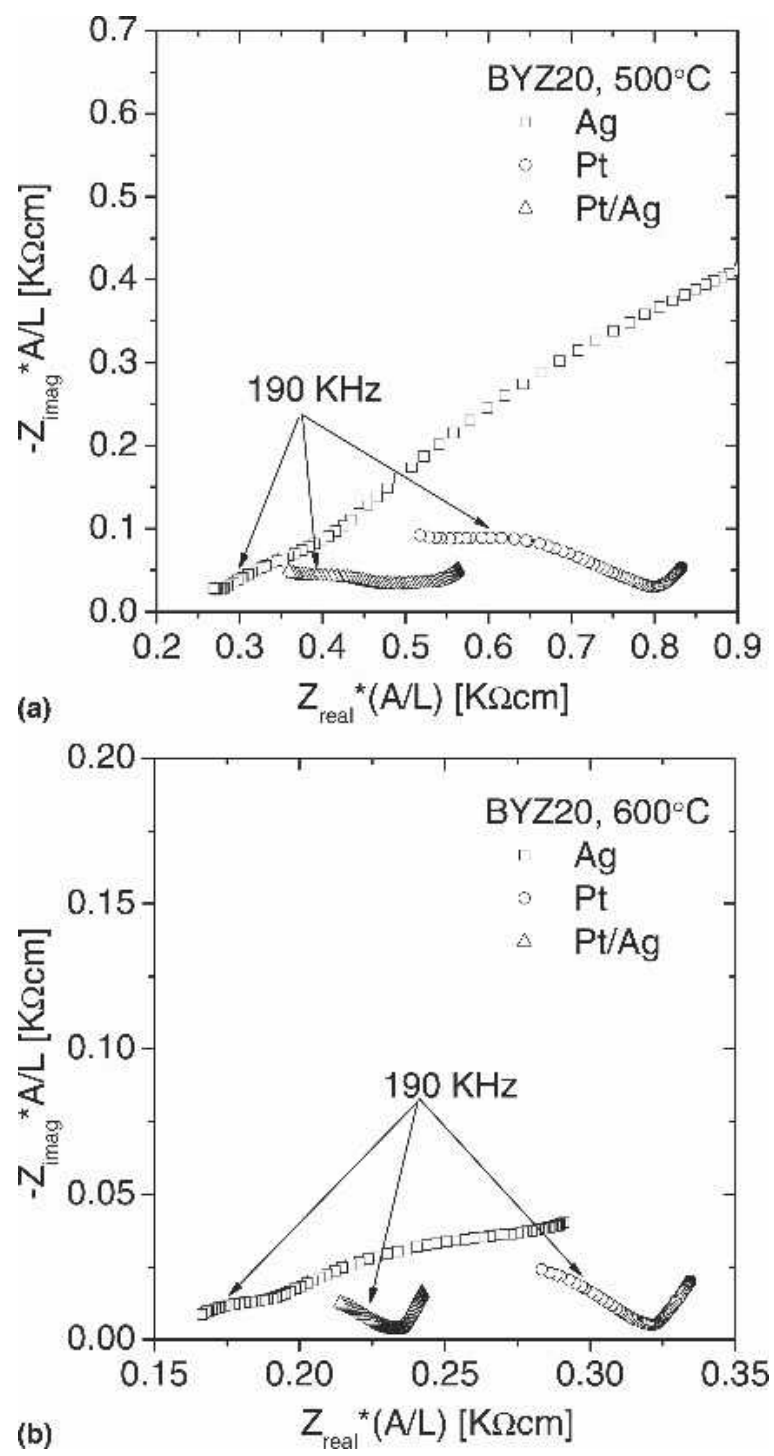

FIG. 6. Nyquist impedance spectra obtained from BYZ20 under humidified nitrogen $\left(p_{\mathrm{H}_{2} \mathrm{O}}=0.03 \mathrm{~atm}\right)$ using the electrodes indicated, at (a) $500{ }^{\circ} \mathrm{C}$ and (b) $600{ }^{\circ} \mathrm{C}$. comparison is made between impedance spectra collected using $\mathrm{Ag}$, those collected using $\mathrm{Pt}$ (fritless $\mathrm{Pt}$ paste, Heraeous Inc., Hanau, Germany; fired at $1100^{\circ} \mathrm{C}$ ), and those collected using fritless $\mathrm{Pt}$ and an additional $\mathrm{Ag}$ layer. Although the spectra were comparable at lower temperatures (data not shown), they are not at the high temperatures at which the electrode processes dominate the impedance response. The Pt-based electrodes give rise to additional electrode resistance effects which, again, can be easily misinterpreted as originating from the electrolyte. The undesirable electrode properties of $\mathrm{Pt}$ may also play a role in the large discrepancies in the reported conductivity values for barium zirconate (Table 1 ).

From the complete fitting of the impedance data (Fig. 5 ), it was possible (depending on the temperature of the measurement) to obtain the resistance, constant phase element parameters, and capacitance, given by $C=$ $Y^{1 / n} R^{(1 / n-1)}$, where $R, Y$, and $n$ are as described previously, for both the bulk and grain-boundary regions of the material. If one assumes that the true dielectric constant of the grain boundaries and the bulk are comparable, then the ratio of the apparent capacitances, $C_{\mathrm{gb}} / C_{\text {bulk }}$, is simply equal to the ratio of the grain diameter, $D$, to the grain-boundary thickness, $\delta .^{27}$ The temperature-averaged value of this ratio was found to be $\sim 140$, and if one takes the grain-boundary thickness to be of the order of $2.5 \mathrm{~nm}$ (as has been observed in Gd-doped barium cerate ${ }^{27}$ ), the implied grain size is of the order of $0.35 \mu \mathrm{m}$. This value agrees well with the observed $0.46 \mu \mathrm{m}$ average grain size in the scanning electron microscopy (SEM) image and confirms the assignment of the midfrequency arc in the impedance spectra to grain-boundary processes.

The respective conductivities were deduced from the resistance terms obtained from the impedance data by accounting for the sample geometry according to Eq. (1):

$$
\sigma=\frac{1}{R} \cdot \frac{L}{A}
$$

where $L$ is the sample thickness and $A$ is its crosssectional area. The grain-boundary conductivity obtained from this simple calculation is a measure of both the grain-boundary geometry (i.e., sample microstructure) and the inherent properties of the grain boundaries. The specific grain-boundary conductivity (independent of microstructure), $\sigma_{\text {sp.gb }}$, was determined, again, under the assumption that the true dielectric constants of the bulk and grain-boundary regions are equal, using the approximation $^{27}$ :

$$
\sigma_{\mathrm{sp} . \mathrm{gb}}=\frac{L}{A}\left(\frac{C_{\mathrm{bulk}}}{C_{\mathrm{gb}}}\right) \frac{1}{R_{\mathrm{gb}}},
$$

and the temperature-averaged (single) value of the ratio $C_{\mathrm{bulk}} / C_{\mathrm{gb}}$. 

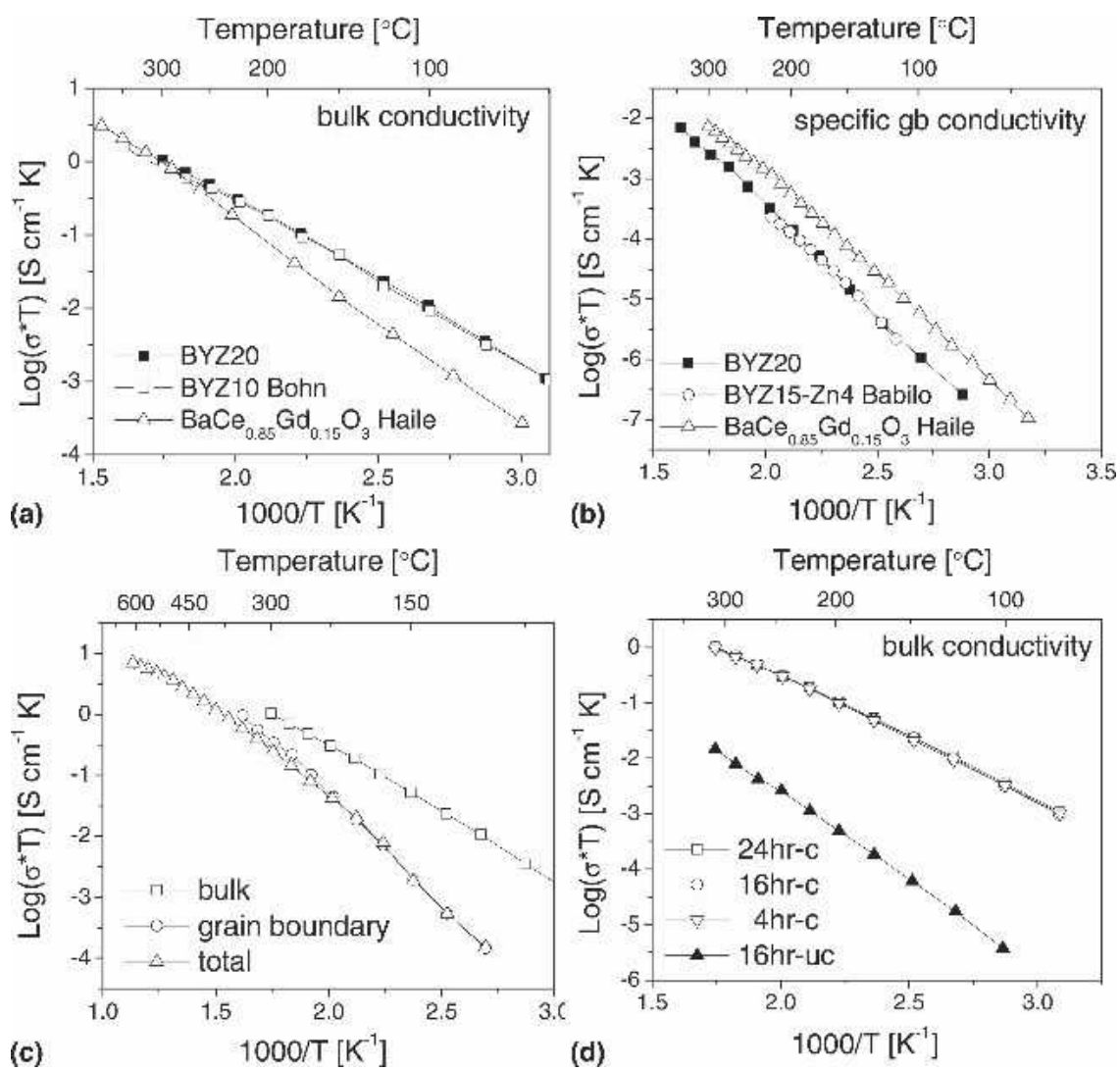

FIG. 7. Conductivity of BYZ20 under humidified nitrogen $\left(p_{\mathrm{H}_{2} \mathrm{O}}=0.03 \mathrm{~atm}\right)$ : (a) bulk (grain interior) conductivity compared to that of $\mathrm{BaZr}_{0.9} \mathrm{Y}_{0.1} \mathrm{O}_{3}(\mathrm{BYZ10})^{7}$ and $\mathrm{BaCe}_{0.85} \mathrm{Gd}_{0.15} \mathrm{O}_{3}{ }^{27}$; (b) specific grain-boundary conductivity (normalized for grain size differences) as compared to that of $\mathrm{BaZr}_{0.85} \mathrm{Y}_{0.15} \mathrm{O}_{3}-(\mathrm{ZnO})_{0.04}(\mathrm{BYZ14}-\mathrm{Zn} 4)^{21}$ and $\mathrm{BaCe}_{0.85} \mathrm{Gd}_{0.15} \mathrm{O}_{3}{ }^{27}$; (c) comparison between grain interior, grain boundary, and total conductivity of BYZ20; and (d) bulk (grain interior) conductivity of BYZ20 sintered for the time periods indicated, where "c" indicates that the sample was covered with excess barium during the sintering step and "uc" that it was not.

The conductivity of BYZ20 derived from the impedance measurements is shown in Fig. 7. Here, the bulk conductivity, the specific grain-boundary conductivity, and the total conductivity [the only quantity that could be measured at high temperatures as evidenced by the form of the impedance spectra in Fig. 5(d)] are all presented. The bulk conductivity obtained for $\mathrm{BaZr}_{0.8} \mathrm{Y}_{0.2} \mathrm{O}_{3-x}$ in this study is comparable to that reported by Bohn and Schober for $\mathrm{BaZr}_{0.9} \mathrm{Y}_{0.1} \mathrm{O}_{3-x},{ }^{7}$ as is the value of the activation energy, supporting our assignment of the highfrequency arc (arc 1) in Fig. 5(a) to bulk processes. Specifically, Bohn and Schober reported an activation energy for bulk conduction under wet argon of $0.44 \pm$ $0.01 \mathrm{eV}$, as compared to the present values of $0.45 \pm 0.01$ $\mathrm{eV}$. The present results also confirm that the bulk conductivity of BYZ20 is, in fact, higher at temperatures lower than $350{ }^{\circ} \mathrm{C}$, than that of typical doped barium cerates, with a correspondingly lower activation energy for proton migration.

As revealed by comparison of Figs. 7(a) and 7(b), the specific grain-boundary conductivity of BYZ20 is much lower than that of the bulk. Simultaneously, the activation energy for proton transport across grain boundaries,
$0.71 \pm 0.02 \mathrm{eV}$, is higher. The grain-boundary behavior of BYZ20 is again similar to that reported by Bohn and Schober for BYZ10, who observed activation energy of $\sim 0.7 \mathrm{eV}$ for proton conduction through the grainboundary regions of their material. This similarity again supports the identification of the midfrequency arc with grain-boundary transport. High grain-boundary resistance to ion transport is typical of ionic conductors ${ }^{28}$ and has also been reported for the related material barium cerate. ${ }^{27}$ Given that the bulk conductivity of barium zirconate is higher than that of barium cerate, it is somewhat surprising that specific grain-boundary resistivity of the zirconate is higher than that of the cerate. Particularly significant for barium zirconate is that the highly refractory properties led to very small grains and consequently a much higher grain-boundary density. As a result, the total conductivity of barium zirconate, that which is the relevant quantity for applications, is much lower than what would be expected simply on the basis of the bulktransport properties [Fig. 7(c)] especially at temperatures of $500{ }^{\circ} \mathrm{C}$ and lower.

The comparison of the properties of BYZ20 that was covered during sintering with that of BYZ20 that was 
not covered [Fig. 7(d)] shows quite dramatically the impact of slight losses of barium from the sample during high-temperature processing. The conductivity of the uncovered pellet has a grain interior conductivity at $100{ }^{\circ} \mathrm{C}$ that is almost 3 orders of magnitude lower than that of the covered pellets. In contrast, three different pellets sintered for differing time periods $(4,16$, and $24 \mathrm{~h})$ exhibit highly reproducible bulk conductivity, despite even slight differences in density (Fig. 2). A discussion of the grain-boundary properties of these samples is presented elsewhere. $^{29}$

The detrimental impact of barium deficiency on the conductivity of doped barium cerate has been well documented $^{24,25}$ and explained in terms of the occupation of the trivalent dopant on the A rather than the B site. These effects, which occur in single-phase materials, are responsible for variations in bulk conductivity by a factor of 2 to $3 .{ }^{24}$ Here it is apparent that the extent of barium oxide sublimation is far more substantial, inducing yttria precipitation within the bulk of the material (Fig. 4) and causing a reduction in conductivity that is 2 orders of magnitude greater than that observed in the cerate. Furthermore, even in barium cerate samples in which barium deficiency is comparable to that observed here for barium zirconate (i.e., similarly induces phase precipitation in the bulk), the decrease in conductivity remains only about a factor of 3 to $4,{ }^{24,27}$ indicating that not only is barium zirconate more susceptible to barium loss because of the required high-temperature processing, the impact is also more significant. While the reasons for such a dramatic influence of barium loss on conductivity remain to be elucidated, it is clear that processing differences must contribute substantially to the significant discrepancy in the reported properties of barium zirconate (Table I). In the present study it was generally observed that the precise placement of uncovered samples relative to one another strongly affected the conductivity, and, while the results presented in Fig. 7(d) for an uncovered sample are representative, by definition, properties under ill-defined conditions are indeterminate.

At high temperatures, because of the higher activation energy of grain-boundary conductivity over conductivity through the bulk, the total conductivity of BYZ20, that which is relevant for applications, becomes dominated by the bulk-transport properties. Thus, despite the high resistivity of the grain boundaries, the total conductivity at $600{ }^{\circ} \mathrm{C}$ was found to be $7.9 \times 10^{-3} \mathrm{~S} / \mathrm{cm}$. Such a value compares favorably to the conductivity of $\mathrm{YSZ}$ at this same temperature, $3.2 \times 10^{-3} \mathrm{~S} / \mathrm{cm} .{ }^{30}$ Furthermore, referring to Table I, it is comparable to the highest reported value for doped barium zirconate and reflects the high conductivity that results when due care is directed toward minimizing barium deficiency in the final material.

\section{SUMMARY AND CONCLUSIONS}

The findings of this study are summarized as follows:

(1) High-density, high-conductivity BYZ can be reproducibly obtained under the processing conditions described. Specifically, the particle size of the starting powder must be less than $100 \mathrm{~nm}$, the green body must be prepared using a binder so as to achieve high green density, and sintering must be carried out under excess barium so as to avoid barium loss. Sintering under oxygen also appears important, but this point requires further investigation.

(2) The total conductivity of $\mathrm{BaZr}_{0.8} \mathrm{Y}_{0.2} \mathrm{O}_{3-x}$ at $600{ }^{\circ} \mathrm{C}$ under humidified nitrogen with $p_{\mathrm{H}_{2} \mathrm{O}}=0.031$ atm is $7.9 \times 10^{-3} \mathrm{~S} / \mathrm{cm}$, where total refers to resistance contributions of both the bulk (grain interior) and grainboundary regions of the material.

(3) In the absence of excess barium, the hightemperature sintering conditions required to achieve good densification of barium zirconate induce measurable changes in stoichiometry and dramatic reductions in proton conductivity. Specifically, barium deficiency was shown to lower the conductivity by 2 orders of magnitude, and it is believed that stoichiometric differences induced by severe processing conditions are the major contributor to the wide variation in literature data for the conductivity of BYZ. Indeed, the recent observation of Iguchi et al. ${ }^{15}$ that prolonged sintering at $1800{ }^{\circ} \mathrm{C}$ lowers the conductivity of $\mathrm{BaZr}_{0.95} \mathrm{y}_{0.05} \mathrm{O}_{3-x}$ by three orders of magnitude may also be attributable to barium loss.

State-of-the-art solid oxide fuel cells (SOFCs) deliver tremendous power densities, as much as $\sim 2 \mathrm{~W} / \mathrm{cm}^{2}$, but they require operation at high temperatures (typically above $800{ }^{\circ} \mathrm{C}$ for SOFCs using yttria-stabilized zirconia as the electrolyte ${ }^{31}$ ). A key motivation for pursuing proton conducting perovskites is the possibility of lowering the fuel cell operating temperature to the 500 to $700{ }^{\circ} \mathrm{C}$ range to alleviate many of the material's lifetime and cyclability challenges that result from very-hightemperature operation. However, to compete with the 2 $\mathrm{W} / \mathrm{cm}^{2}$ of power output possible from conventional SOFCs, improvements in both the conductivity of BYZ and the electrocatalysis rates at its electrodes are required. While attaining these improvements, via for example optimizing the doping, enhancing grain growth, and exploring alternative electrocatalysts, will undoubtedly require substantial efforts, development of the procedures for obtaining reproducible transport properties reported here constitutes a critical first step toward implementation of barium zirconate in commercially viable devices.

\section{ACKNOWLEDGMENTS}

Funding for this work was provided by the United States Department of Energy through the National 
Energy Technology Laboratory, Office of Fossil Fuels (DE-FC26-02NT41631). Additional support was provided by the United States National Science Foundation (DMR-0080065) through Caltech's Center for the Science and Engineering of Materials, an NSF Materials Research Science and Engineering Center (MRSEC).

\section{REFERENCES}

1. N. Ito, M. Iijima, K. Kimura, and S. Iguchi: New intermediate temperature fuel cell with ultra-thin proton conductor electrolyte. J. Power Sources 152, 200 (2005).

2. K.D. Kreuer: Aspects of the formation and mobility of protonic charge carriers and the stability of perovskite-type oxides. Solid State Ionics 125, 285 (1999).

3. K.H. Ryu and S.M. Haile: Chemical stability and proton conductivity of doped $\mathrm{BaCeO}_{3}-\mathrm{BaZrO}_{3}$ solid solutions. Solid State Ionics 125, 355 (1999).

4. H. Iwahara, T. Yajima, T. Hibino, K. Ozaki, and H. Suzuki: Protonic conduction in calcium, strontium and barium zirconates. Solid State Ionics 61, 65 (1993).

5. A. Manthiram, J.F. Kuo, and J.B. Goodenough: Characterization of oxygen-deficient perovskites as oxide-ion electrolytes. Solid State Ionics 62, 225 (1993).

6. R.C.T. Slade, S.D. Flint, and N. Singh: Investigation of protonic conduction in $\mathrm{Yb}$ - and Y-doped barium zirconates. Solid State Ionics 82, 135 (1995).

7. H.G. Bohn and T. Schober: Electrical conductivity of the hightemperature proton conductor $\mathrm{BaZr}_{0.9} \mathrm{Y}_{0.1} \mathrm{O}_{2.95}$. J. Am. Ceram. Soc. 83, 768 (2000).

8. K. Katahira, Y. Kohchi, T. Shimura, and H. Iwahara: Protonic conduction in $\mathrm{Zr}$-substituted $\mathrm{BaCeO}_{3}$. Solid State Ionics 138.91 (2000).

9. V.P. Gorelov, V.B. Balakireva, Y.N. Kleshchev, and V.P. Brusentsov: Preparation and electrical conductivity of $\mathrm{BaZr}_{1-x} \mathrm{R}_{x} \mathrm{O}_{3-\alpha}(\mathrm{R}=$ Sc, Y, Ho, Dy, Gd, In). Inorg. Mater. 37, 535 (2001).

10. M. Laidoudi, I. Abu Talib, and R. Omar: Investigation of the bulk conductivity of $\mathrm{BaZr}_{0.95} \mathrm{M}_{0.05} \mathrm{O}_{3}(\mathrm{M}=\mathrm{Al}, \mathrm{Er}, \mathrm{Ho}, \mathrm{Tm}, \mathrm{Yb}$ and $\mathrm{Y})$ under wet $\mathrm{N}_{2}$. J. Phvs. D Appl. Phvs. 35, 397 (2002).

11. K.D. Kreuer: Proton-conducting oxides. Ann. Rev. Mater. Res. 33 $333(2003)$.

12. F.M.M. Snijkers, A. Buekenhoudt, J. Cooymans, and J.J. Luyten: Proton conductivity and phase composition in $\mathrm{BaZr}_{0.9} \mathrm{Y}_{0.1} \mathrm{O}_{3^{-}}$ Delta. Scripta Mater. 50, 655 (2004).

13. W.S. Wang and A.V. Virkar: Ionic and electron-hole conduction in $\mathrm{BaZr}_{0.93} \mathrm{Y}_{0.07} \mathrm{O}_{3-\delta}$ by 4-probe D.C. measurements. $\underline{\text { J. Power }}$ Sources 142, 1 (2005).

14. C.D. Savaniu, J. Canales-Vazquez, and J.T.S. Irvine: Investigation of proton conducting $\mathrm{BaZr}_{0.9} \mathrm{Y}_{0.1} \mathrm{O}_{2.95}: \mathrm{BaCe}_{0.9} \mathrm{Y}_{0.1} \mathrm{O}_{2.95}$ coreshell structures. J. Mater. Chem. 15, 598 (2005).
15. F. Iguchi, T. Yamada, N. Sata, T. Tsurui, and H. Yugami: The influence of grain structures on the electrical conductivity of a $\mathrm{BaZr}_{0.95} \mathrm{Y}_{0.05} \mathrm{O}_{3}$ proton conductor. Solid State Ionics 177, 2281 (2006).

16. L.A. Chick, L.R. Pederson, G.D. Maupin, J.L. Bates, L.E. Thomas, and G.J. Exarhos: Glycine nitrate combustion synthesis of oxide ceramic powders. Mater. Lett. 10, 6 (1990).

17. J.T. Armstrong: CITZAF: A package of correction programs for the quantitative electron microbeam x-ray analysis of thick polished materials, thin films, and particles. Microbeam Anal. 4, 177 (1995).

18. J.R. MacDonald and W.B. Johnson: Impedance SpectroscopyEmphasizing Solid Materials and Systems, edited by J.R. MacDonald (Wiley and Sons, New York, 1987), pp. 191-238.

19. K.D. Kreuer, S. Adams, W. Munch, A. Fuchs, U. Klock, and J. Maier: Proton conducting alkaline earth zirconates and titanates for high drain electrochemical applications. Solid State Ionics $\mathbf{1 4 5}$ 295 (2001).

20. A. Kojima, K. Tanaka, Y. Oyama, T. Higuchi, and S. Yamaguchi: The 31st Symposium on Solid State Ionics in Japan, Niigata, Japan, Nov. 28-30, 2005 (The Mining and Materials Processing Institute of Japan, 2006), p. 157.

21. P. Babilo and S.M. Haile: Enhanced sintering of yttrium-doped barium zirconate by addition of ZnO. J. Am. Ceram. Soc. 88, 2362 (2005).

22. A. Magrez and T. Schober: Preparation, sintering, and water incorporation of proton conducting $\mathrm{Ba}_{0.99} \mathrm{Zr}_{0.8} \mathrm{Y}_{0.2} \mathrm{O}_{3-\delta}$ : Comparison between three different synthesis techniques. Solid State Ionics 175, 585 (2004).

23. G. Baldinozzi, J.F. Berar, and G. Calvarin: Rietveld refinement of two-phase Zr-doped $\mathrm{Y}_{2} \mathrm{O}_{3}$. Mater. Sci. Forum 278-2, 680 (1998).

24. D. Shima and S.M. Haile: The influence of cation nonstoichiometry on the properties of undoped and gadolinia-doped barium cerate. Solid State Ionics 97, 443 (1997).

25. J. Wu, L.P. Li, W.T.P. Espinosa, and S.M. Haile: Defect chemistry and transport properties of $\mathrm{Ba}_{x} \mathrm{Ce}_{0.85} \mathrm{M}_{0.15} \mathrm{O}_{3-\delta}$. J. Mater. Res. 19, 2366 (2004).

26. J. Wu, S.M. Webb, S. Brennan, and S.M. Haile: Dopant site selectivity in $\mathrm{BaCe}_{0.85} \mathrm{M}_{0.15} \mathrm{O}_{3-\delta}$ by extended $\mathrm{x}$-ray absorption fine structure. J. Appl. Phvs. 97, 054101 (2005).

27. S.M. Haile, D.L. West, and J. Campbell: The role of microstructure and processing on the proton conducting properties of gadolinium-doped barium cerate. J. Mater. Res. 13, 1576 (1998).

28. X. Guo and R. Waser: Space charge concept for acceptor-doped zirconia and ceria and experimental evidences. Solid State Ionics 173, 63 (2004).

29. P. Babilo and S.M. Haile (under preparation).

30. B.C.H. Steele: Oxygen ion conductors and their technological applications. Mater. Sci. Eng. B 13, 79 (1992).

31. S.M. Haile: Fuel cell materials and components. Acta Mater. 51. 5981 (2003). 